\section{$\mathbf{V} \mathbf{M}$ \\ VIA MEDICA www.fr.viamedica.pl}

\title{
Renal amyloidosis secondary to rheumatoid arthritis effectively treated with tocilizumab
}

\section{ABSTRACT}

Kidney amyloidosis is one of the most serious potential complication of chronic inflammatory disorders, including rheumatoid arthritis. Interleukin-6 blockade is frequently effective in rheumatic disease, however, there are only few published data on its use in $A A$ amyloidosis. Here, we report a case of patient with rheumatoid arthritis complicated by nephrotic syndrome due to secondary type A amyloidosis successfully treated with tocilizumab.

Forum Reumatol. 2018, tom 4, nr 3: 184-186

Key words: rheumatoid arthritis; kidney amyloidosis; tocilizumab

\section{INTRODUCTION}

Amyloidosis is a heterogeneous group of diseases in which insoluble protein fibres with an abnormal structure and resistant to proteolysis build up in the extracellular space [1]. Localised or systemic forms of the disease are distinguished depending on whether deposits build up in one or in many organs [1]. The kidneys are among the most affected organs [2].

Amyloidosis is classified on the basis of the type of protein precursor that makes the majority of deposits. The names of amyloidosis variations start with the letter " $\mathrm{A}$ " and include other letters, which refer to the type of abnormal protein [3]. Traditionally, amyloidosis is divided into primary and secondary. Primary amyloidosis (AL) is associated with monoclonal gammopathy and other types of leukaemia [1]. Secondary amyloidosis (AA) is secondary to chronic inflammatory diseases in the majority of cases [4].

Nowadays, amyloidosis is primarily caused by non-infectious inflammatory diseases. It is most common in rheumatoid arthritis (RA) and constitutes 5-20\% of complications of rheumatic diseases. The kidneys are among the most affected organs $[4,5]$.
Renal amyloidosis is a consequence of a chronic inflammatory process that involves the deposition of insoluble AA protein in the glomeruli. Acute-phase SAA protein is the precursor of the A amyloid. It is produced in the liver and transported by high-density lipoproteins [5]. The most common first symptom of kidney involvement in renal amyloidosis includes nephrotic range proteinuria and progressive kidney failure. Kidney involvement may be accompanied by diarrhoea, malabsorption, and cardiomyopathy. The diagnosis of renal amyloidosis is confirmed by a histological examination of a kidney biopsy specimen [6].

The treatment of this disease is difficult and closely related to the treatment of the underlying disease. The lower the activity of the underlying disease, the higher the chance of preventing the development of renal amyloidosis. Causal treatment involves reducing the production of protein precursors of amyloid fibrils (SAA) through limiting inflammation [7]. Therefore, appropriately selected classic disease-modifying antirheumatic drugs and the retention of a low activity of the disease may inhibit the development of amyloidosis. However, it is currently believed that biological 
drugs are first-choice drugs in the treatment of AA amyloidosis secondary to RA [6, 7].

\section{CASE STUDY}

This paper presents a 57-year-old patient with secondary amyloidosis secondary to rheumatoid arthritis, in whom biological treatment (tocilizumab) was effective.

The patient has long-term and active rheumatoid arthritis, which was diagnosed in 2001. The treatment included methotrexate, sulfasalazine, and leflunomide one by one in standard recommended doses as well as periodically administered nonsteroidal anti-inflammatory drugs (NSAIDs) and corticosteroids. However, disease remission was only partial.

In May 2014, nephrotic range proteinuria (up to $5 \mathrm{~g} /$ day) was diagnosed, while the excretory function of the kidneys was normal (glomerular filtration rate [eGFR] > $90 \mathrm{ml} / \mathrm{min} / 1.73 \mathrm{~m}^{2}$ ). In September 2014, renal amyloidosis was diagnosed based on the examination of a kidney biopsy specimen. As a result, the patient began to be treated with cyclophosphamide in November 2014 (800 mg i.v. acc. to the standard regiment; $4.0 \mathrm{~g}$ of the drug was administered in total). In spite of the treatment, treatment response was not significant (persistent nephrotic range proteinuria). In June 2015, the patient started to be treated with cyclosporin A (controlled via drug concentration in the serum), but no significant reduction of proteinuria was achieved.

Given the ineffectiveness of synthetic disease-modifying antirheumatic drugs, biological treatment with tocilizumab was initiated (in a dose of $8 \mathrm{mg} / \mathrm{kg} \mathrm{m.c.} \mathrm{i.v.,} \mathrm{acc.} \mathrm{to} \mathrm{the} \mathrm{standard}$ regime $1 \times / 4$ weeks). At the start of the treatment, the disease activity in the patient was high: $\mathrm{DAS}-28=5.63, \mathrm{OB}=36 \mathrm{~mm} / \mathrm{h}$, proteinuria $=1.8 \mathrm{~g} /$ day. The tocilizumab treatment resulted in a partial remission of the underlying disease and a considerable reduction of proteinuria that is still present. After 18 months from the beginning of the treatment, the disease activity in the patient was as follows: DAS-28 $<3.2$; $\mathrm{OB}<20 \mathrm{~mm} / \mathrm{h}$; proteinuria $<0.3 \mathrm{~g} /$ day. Furthermore, the excretory function of the kidneys is still normal (eGFR $>90 \mathrm{ml} / \mathrm{min} / 1.73 \mathrm{~m}^{2}$ ).

\section{DISCUSSION}

Tocilizumab is a recombinant humanized monoclonal antibody of an immunoglobulin G1 (IgG1) subclass against interleukin-6 receptors: both soluble receptors (sIL-6R) and membrane receptors (mIL-6R). It has been proven that tocilizumab inhibits signal transduction mediated by both mIL-6R and sIL-6R [8]. It is effectively used to treat rheumatoid arthritis also in patients after an ineffective treatment with inhibitors of tumour necrosis factor $\alpha(\mathrm{TNF}-\alpha)$ [9]. In the literate, there are reports on the effectiveness of the IL- 6 blockade in the case of amyloidosis secondary to rheumatic diseases, the prognosis of which has been very unfavourable so far [10]. The first description of the effectiveness of tocilizumab in treating secondary amyloidosis was published as early as in 2006 [11]. In the following years, it was proven that the use of tocilizumab to treat renal amyloidosis secondary to rheumatic diseases reduces proteinuria and allows the renal function to be normal for a longer time which, in turn, delays the necessity to begin renal replacement therapy [10, 12-14]. Therefore, it seems that tocilizumab is the drug of first choice for amyloidosis secondary to rheumatic diseases.
1. Mohamed N, Nasr SH. Renal Amyloidosis. Surg Pathol Clin. 2014; 7(3): 409-425, doi: 10.1016/j.path.2014.04.006, indexed in Pubmed: 26837447.

2. Wang YH, Zhang YG. Amyloid and immune homeostasis. Immunobiology. 2017, doi: 10.1016/j.imbio.2017.10.038.

3. Cohen A, Jones L. Amyloidosis. Current Opinion in Rheumatology. 1991; 3(1): 125-138, doi: 10.1097/00002281199102000-00018.

4. Horak P, Smrzova A, Krejci K, et al. Renal manifestations of rheumatic diseases. A review. Biomed Pap Med Fac Univ Palacky Olomouc Czech Repub. 2013; 157(2): 98-104, doi: 10.5507/bp.2013.042, indexed in Pubmed: 23752767.

5. Obici L, Merlini G. AA amyloidosis: basic knowledge, unmet needs and future treatments. Swiss Med Wkly. 2012;
142: w13580, doi: 10.4414/smw.2012.13580, indexed in Pubmed: 22653707.

6. Król E, Perkowska-Ptasińska A, Oko A. Kidney involvement in rheumatoid arthritis - diagnostic and management recommendations. Nefrol Dial Pol. 2016; 20: 127-133.

7. Mittal T, Rathi M. Rheumatological diseases and kidneys: a nephrologist's perspective. Int J Rheum Dis. 2014; 17(8): 834-844, doi: 10.1111/1756-185X.12424, indexed in Pubmed: 24952962.

8. Shetty A, Hanson R, Korsten P, et al. Tocilizumab in the treatment of rheumatoid arthritis and beyond. Drug Des Devel Ther. 2014; 8: 349-364, doi: 10.2147/DDDT.S41437, indexed in Pubmed: 24729685.

9. Smolen JS, Landewe R, Bijlsma J. EULAR recommendations for the management of rheumatoid arthritis with 
synthetic and biological disease-modifying antirheumatic drugs: 2016 update. Annals of the rheumatic diseases. 2017; 76(6): 960-977, doi: 10.1136/annrheumdis-2016-210715.

10. Courties A, Grateau G, Philippe P, et al. Club Rhumatismes Inflammation and the REGATE Registry. AA amyloidosis treated with tocilizumab: case series and updated literature review. Amyloid. 2015; 22(2): 84-92, doi: 10.3109/13506129.2014.1002031, indexed in Pubmed: 25585627.

11. Okuda $Y$, Takasugi K. Successful use of a humanized anti-interleukin-6 receptor antibody, tocilizumab, to treat amyloid A amyloidosis complicating juvenile idiopathic arthritis. Arthritis Rheum. 2006; 54(9): 2997-3000, doi: 10.1002/art.22118, indexed in Pubmed: 16947531.
12. Vinicki JP, De Rosa G, Laborde HA. Renal amyloidosis secondary to rheumatoid arthritis: remission of proteinuria and renal function improvement with tocilizumab. J Clin Rheumatol. 2013; 19(4): 211-213, doi: 10.1097/RHU. 0b013e318293793c, indexed in Pubmed: 23669800.

13. Miyagawa I, Nakayamada S, Saito K, et al. Study on the safety and efficacy of tocilizumab, an anti-IL-6 receptor antibody, in patients with rheumatoid arthritis complicated with AA amyloidosis. Mod Rheumatol. 2014; 24(3): 405-409, doi: 10.3109/ 14397595.2013.844294, indexed in Pubmed: 24252016.

14. Uda H, Saiki O. Tocilizumab postpones the start of hemodialysis compared to conventional oral treatment in amyloid $A$ amyloidosis patients with advanced renal insufficiency by suppressing serum SAA levels. Amyloid. 2017; 24(1): 62-63, doi: 10.1080/ 13506129.2017.1301420, indexed in Pubmed: 28393636. 


\section{Amyloidoza nerek w przebiegu reumatoidalnego zapalenia stawów skutecznie leczona tocilizumahem}

Artykuł jest tłumaczeniem pracy: Doroty Sikorskiej i Włodzimierza Samborskiego. Renal amyloidosis secondary to rheumatoid arthritis effectively treated with tocilizumab — case study. Forum Reumatol. 2018 tom 4, nr 3: 184-186. Należy cytować wersję pierwotną.

Piśmiennictwo znajduje się na stronach 185-186.

\section{STRESZCZENIE}

Amyloidoza nerek jest jednym z poważniejszych powikłań przewlekłych chorób zapalnych, w tym reumatoidalnego zapalenia stawów. Blokada receptora dla inteleukiny 6 jest obecnie z powodzeniem stosowana w leczeniu chorób reumatycznych, jednak niewiele jest doniesień na temat jej skuteczności w przypadku leczenia wtórnej amyloidozy. W niniejszym artykule przedstawiono przypadek pacjenta z amyloidozą nerek w przebiegu reumatoidalnego zapalenia stawów skutecznie leczonego tocilizumabem.

Forum Reumatol. 2018, tom 4, nr 3: 187-188

Słowa kluczowe: reumatoidalne zapalenie stawów; amyloidoza nerek; tocilizumab

\section{WSTEP}

Amyloidozy są heterogenną grupą chorób, których istotą jest gromadzenie się w przestrzeni pozakomórkowej nierozpuszczalnych włókien białkowych o nieprawidłowej strukturze, opornych na proteolizę [1]. W zależności od tego, czy odkładanie się złogów jest ograniczone do jednego, czy wielu narządów, mówi się o miejscowych lub uogólnionych postaciach choroby [1]. Jednym z częściej zajętych narządów są nerki [2].

Klasyfikacja amyloidozy oparta jest na rodzaju białka prekursorowego, które jest najważniejszym składnikiem złogów. Nomenklatura amyloidozy składa się z litery A i następnych liter, określających rodzaj nieprawidłowego białka [3]. Amyloidozę tradycyjnie dzieli się na pierwotną i wtórną. Pierwotna (AL) wiąże się z gammapatią monoklonalną i innymi nowotworami układu krwiotwórczego [1]. Amyloidoza wtórna (AA) występuje w większości przypadków w przebiegu przewlekłych chorób zapalnych [4].
Obecnie skrobiawica jest w większości przypadków wywołana przez nieinfekcyjne choroby zapalne. Dominuje w reumatoidalnym zapaleniu stawów (RZS) i stanowi 5-20\% powikłań chorób reumatologicznych. Jednym z częściej zajętych narządów są nerki [4, 5].

Amyloidoza nerek jest następstwem przewlekłego procesu zapalnego przebiegającego z odkładaniem się w kłębuszkach nerkowych nierozpuszczalnego białka AA. Prekursorem amyloidu A jest białko ostrej fazy SAA produkowane w wątrobie i transportowane przez lipoproteiny o dużej gęstości [5]. Najczęściej pierwszym objawem zajęcia nerek w skrobiawicy jest białkomocz w granicach zespołu nerczycowego i postępująca niewydolność nerek. Zajęciu nerek może towarzyszyć biegunka i zespół złego wchłaniania oraz kardiomiopatia. Rozpoznanie potwierdza się badaniem histologicznym bioptatu nerki [6].

Leczenie skrobiawicy nerek jest trudne i ściśle związane z leczeniem choroby podstawowej. Im niższa jest aktywność choroby zasadniczej, tym większa szansa na niedopusz-
Adres do korespondencji: dr n. med. Dorota Sikorska Katedra Reumatologii i Rehabilitacji Uniwersytet Medyczny im. Karola Marcinkowskiego w Poznaniu ul. 28 Czerwca 1956 r. 135/147 61-545 Poznań tel.: 618310244 faks: 618310244 e-mail: dorotasikorska@ump.edu.pl 
czenie do rozwoju amyloidozy nerek. Leczenie przyczynowe obejmuje zmniejszenie wytwarzania białek prekursorowych włókien amyloidu (SAA), poprzez ograniczenie stanu zapalnego [7]. W związku z tym, odpowiednio dobrane klasyczne leki modyfikujące przebieg choroby i utrzymanie niskiej aktywności choroby moga hamować rozwój amyloidozy. Jednak obecnie uważa się, że lekami z wyboru w leczeniu skrobiawicy AA w przebiegu RZS są leki biologiczne $[6,7]$.

\section{OPIS PRZYPADKU}

W niniejszym artykule przedstawiono przypadek 57-letniego chorego z amyloidozą wtórną w przebiegu RZS, u którego zastosowano $\mathrm{z}$ powodzeniem leczenie biologiczne (tocilizumab).

Pacjent z wieloletnim, aktywnym RZS, rozpoznanym w 2001 roku. W procesie leczenia stosowano kolejno: metotreksat, sulfasalazynę, leflunomid, w standardowych zalecanych dawkach, oraz okresowo niesteroidowe leki przeciwzapalne (NLPZ) i glikokortykosteroidy, uzyskując tylko częściową remisję choroby.

W maju 2014 roku stwierdzono białkomocz o wartościach nerczycowych (do $5 \mathrm{~g}$ /dobę), przy prawidłowej funkcji wydalniczej nerek (wielkość filtracji kłębuszkowej [eGFR, glomerular filtration rate] $>90 \mathrm{ml} / \mathrm{min} / 1,73 \mathrm{~m}^{2}$ ). We wrześniu 2014 roku, na podstawie wykonanej biopsji nerki, postawiono rozpoznanie amyloidozy nerek. W związku z tym, w listopadzie 2014 roku rozpoczęto leczenie cyklofosfamidem (800 mg i.v. wg standardowego schematu; łącznie podano 4,0 g leku). Mimo zastosowanego leczenia nie uzyskano istotnej odpowiedzi na leczenie (utrzymujący się białkomocz o wartościach nerczycowych). W czerwcu 2015 roku rozpoczęto leczenie cyklosporyną A (pod kontrolą stężenia leku w surowicy), również nie uzyskując istotnej redukcji białkomoczu.

Z uwagi na nieskuteczność syntetycznych leków modyfikujących przebieg choroby, w grudniu 2015 roku rozpoczęto le- czenie biologiczne tocilizumabem (w dawce $8 \mathrm{mg} / \mathrm{kg} \mathrm{mc}$. i.v. wg standardowego schematu $1 \times / 4$ tyg.). W momencie rozpoczęcia leczenia pacjent wykazywał wysoką aktywność choroby: DAS-28 = 5,63, OB $=36 \mathrm{~mm} / \mathrm{h}$, białkomocz $=1,8 \mathrm{~g} /$ dobę. Po zastosowanym leczeniu uzyskano częściową remisję choroby podstawowej oraz znaczną redukcję białkomoczu, która utrzymuje się do chwili obecnej. Po 18 miesiącach leczenia u chorego obserwowano: DAS-28 < 3,2; OB $<20 \mathrm{~mm} / \mathrm{h}$; białkomocz $<0,3 \mathrm{~g} /$ dobę. Ponadto, nadal zachowana jest prawidłowa funkcja wydalnicza nerek (eGFR > $90 \mathrm{ml} / \mathrm{min} / 1,73 \mathrm{~m}^{2}$ ).

\section{DYSKUSJA}

Tocilizumab jest rekombinowanym humanizowanym przeciwciałem monoklonalnym podklasy immunoglobuliny G1 (IgG1), skierowanym przeciwko receptorom interleukiny 6 , zarówno rozpuszczalnym (sIL-6R), jak i związanym z błonami komórkowymi (mIL-6R). Wykazano, że tocilizumab hamuje przekazywanie sygnału dwoma szlakami pośredniczącymi przez sIL-6R i mIL-6R [8]. Tocilizumab jest $\mathrm{z}$ powodzeniem stosowany $\mathrm{w}$ leczeniu RZS, także w przypadku chorych po nieskutecznym leczeniu inhibitorami czynnika martwicy nowotworów $\alpha$ (TNF- $\alpha$; tumor necrosis factor alpha) [9]. W piśmiennictwie pojawiają się również doniesienia na temat skuteczności blokady szlaku IL-6 w przypadku amyloidozy wtórnej do chorób reumatycznych, która dotychczas rokowała bardzo niekorzystnie [10]. Pierwszy opis skuteczności tocilizumabu w leczeniu wtórnej amyloidozy pojawił się już w 2006 roku [11]. W późniejszych latach potwierdzono, że zastosowanie tocilizumabu w leczeniu skrobiawicy nerek wtórnej do chorób reumatycznych pozwala na redukcję białkomoczu, a także pozwala dłużej utrzymać prawidłową funkcję nerek, opóźniając konieczność rozpoczęcia leczenia nerkozastępczego [10, 12-14]. Zatem wydaje się, że tocilizumab jest lekiem z wyboru w przypadku amyloidozy wtórnej do chorób reumatycznych. 